\title{
A Review on Teen Drug Use: Risks and Protective Factors
}

\author{
Dr Rejani T.G
}

\section{Keywords: Drug, Protective Factor}

\section{INTRODUCTION:}

Drug use and abuse among adolescence is a major issue in a society. Studies have tried to determine the origins and pathways of drug abuse and addiction-how the problem starts and how it progresses. . Many factors have been identified that help differentiate those more likely to abuse drugs from those less vulnerable to drug abuse. Factors associated with greater potential for drug abuse are called "risk" factors, while those associated with reduced potential for abuse are called "protective" factors (NIDA, 1997). Studies have reported various risk factors associated with drug use among adolescents such as early aggressive behavior, disinhibition, peer pressure, drug availability, poverty, substance abuse, lack of parental supervision, attitude towards drug use and intentions to use drugs, negative family atmosphere, school difficulties and psychopathology (Wong, Tang and Schwarzer,1996 ; Rumpold et al , 2011). Protective factors such as parental monitoring and peer support were found to be associated with less drug abuse (Vitaro, Tremblay and Zoccolillo, 1999; Eggert and Herting, 1991).

The potential impact of specific risk and protective factors changes with age and can affect people of all groups, these factors can have a different effect depending on a person's age, gender, ethnicity, culture, and environment (Moon et al. 1999; Kumpfer et al. 1998). This review would focus on the various risks and protective factors related to drug use among adolescents under the domain of individual, family, peer, school and community.

\section{Risk factors:}

\section{Individual domain}

Many individual characteristics can predispose a person to use drugs such as gender, age, disinhibition, early aggressive behavior, attitude towards drug use and intention to use drugs.

\footnotetext{
${ }^{1}$ Assistant Professor, Gujarat Forensic Sciences University, Gandhinagar, Gujarat, India
} 


\section{Gender:}

Many studies have pointed out that male has a greater likelihood of use or abuse of drugs(Schepis, Desai, Cavallo, Smith , McFetridge, Liss, Potenza and Krishnan-Sarin, 2011; Mousavi , Garcia , Jimmefors, Archer, Ewalds-Kvist , 2014).

\section{Age:}

Many studies have pointed out that onset of alcohol and drug use usually occurs at adolescence period and associated with heavy drinking and consumption in adulthood. Adolescents start tobacco consumption between 12-13 years, alcohol at 13, cannabis at 14 synthetic drugs at 13 and cocaine between 14 and 15 (Martí, Fernández, \& Rodríguez, 2011).Liang and Chikritzhs(2014) found that age at first use of alcohol before 18 years was associated significantly higher risk of heavy alcohol use at follow-up. Adolescents with early drinking onset were more likely to show heavier alcohol use, more drunkenness episodes, and more drug use than adolescents with late drinking onset (Pilatti, Godoy , Brussino\& Pautassi, 2013). An increase in lifetime prevalence and lower age for consumption onset were noticed by OspinaDíaz, Herrera-Amaya, \& Manrique-Abril(2012).

\section{Disinhibition:}

Behaviouraldisinhibition (i.e.,high novelty seeking, impulsivity, lack of constraint; Sher\&Trull, 1994 ) is associated with drug use. Sensation seeking has been widely implemented as a proxy for trait disinhibition (McCarthy, Miller, Smith\& Smith, 2001). Individual differences in behavioral disinhibition are manifestations ofunderlying central nervous system processes associated with various psychophysiological anomalies, some of which may index genetic risk for substance abuse (Iacono, Carlson, Taylor, Elkins and Mcgue, 1999). Studies have reported that disinhibition is associated with drug use in adolescents and young adults (Ridenour, Tarter, Reynolds, Mezzich, Kirisci and Vanyukov, 2009; Mousavi, Garcia, Jimmefors, Archer, \& Ewalds-Kvist, 2014)

\section{Intention to use drugs and early aggressive behavior:}

Intention to use drug can predict drug related behavior (Schlegel, Crawford, \& Sanborn, 1977). Child temperament is very crucial factor in determining the future use of drugs. Difficult temperament characterized by aggressive behavior in childhood is closely associated with drug use in adolescents (Torok, Darke, Kaye \& Shand, 2014). 


\section{Attitude towards drug use:}

Attitudes have been hypothesized to influence experimentation with drugs and continued substance use. It was found that initiation into drug use of any substance is preceded by values favorable to its use. Although attitudes of adolescents toward drugs have no direct influence on their drug use, attitudes affect use indirectly, through behavioral intentions. Favorable attitudes increase behavioral intentions which in turn affect the probability of use (Kandel et al., 1978; Krosnick \& Judd, 1982;Barnea et al.1992).In another study, it was found that men had more positive attitudes toward "drug" vignette. The most negative attitudes were found toward "heroin" vignette and the most positive attitudes were found toward the "cannabis" vignette. Results indicated that those who has known a drug user had more positive attitudes (Cem, 1rakog, lu, Gu“ ler Ic,ns1,2005). In a recent study, positive attitudes towards drugs and impulsiveness are found to predict drug usage in adolescents (Mousavi, Garcia , Jimmefors, Archer, \& Ewalds-Kvist, 2014).

\section{Psychiatric illness and co morbidities:}

Psychiatric illness and co morbidities in childhood and adolescence are found to be risk factor for later drug abuse/substance abuse. Disorders like ADHD and conduct disorders have found to have strong relation with substance abuse in adulthood (Kousha M, Shahrivar Z, Alaghband-Rad J., 2011). Patients with mental illness are at high risk for substance abuse, and the adverse impact on cognition may be particularly deleterious in combination with cognitive problems related to their mental disorders (Gould,2010). It is also found that childhood adversities, a pre-existing mood disorder, personality disorder, previous nicotine dependence, and alcohol abuse or dependence are associated with drug use (Drazdowski, Jäggi, Borre,\& Kliewer,2014;VermeulenSmit, Ten Have, Van Laar, De Graaf, 2014). Specific mental disorders independently increase the risk of progression to incident drug use among people who were previously abstinent (Harrington, Robinson, Bolton, Sareenand Bolton,2011). Different co morbid disorders were

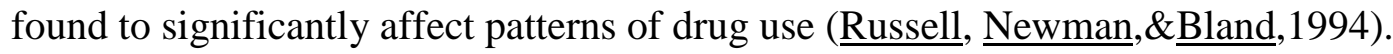

\section{Family domain}

\section{Dysfunctional family:}

Children and adults from dysfunctional families and history of childhood traumatic experiences are more prone to drug use and drug abuse. An obedience-instilling parenting style and parents' knowledge and attitude toward drug using and prevention were also identified as important

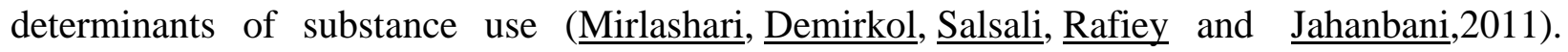
Children of "permissive parents" who are more accepting of drugs and liquor or who leave decisions about them to their teens are more likely to have children who abuse substances. Family conflict and home management problems are found to be contributing factors in drug 
abuse risk. Moreover, Paternal alcoholism was an important risk factor in the development of substance abuse problems in adolescence (itaro, Tremblay and Zoccolillo,1999). Single-parent and reconstructed families were related to the greatest likelihood of substance use(Scalese, Curzio,Cutrupi, Bastiani,Gori, Denoth,\& Molinaro, 2014).

\section{Peer domain}

\section{Peer pressure}

Many studies have been reported that peer pressure is one of the strongest predictors of substance use in adolescents (Kandel,1980; zucker,1979; Rumpold, Klingseis, Dornauer, Kopp, Doering, Höfer, Mumelter and Schüssler ,2011;Jadidi\& Nakhaee, 2014). The relationship between peer pressure and drug use was stronger among girls than boys, and also among adolescents in families without fathers or stepfathers. The association between peer pressure and drug use also increased as a function of the level of mother-adolescent distress among adolescents who were not living with fathers or stepfathers. The association between peer drug models and drug use increased as a function of the level of mother-adolescent distress (Farrell, Albert; White, Kamila,1998). Perceived peer attitudes and peer's drug use behaviours influence adolescents' drug use (Stanton \& Silva, 1992).

Susceptibility to peer pressure emerged as the most important predictor of adolescent alcohol and drug use (Dielman, Butchart, Shope and Miller ,1990); Dielman, Campanelli, Shope and Butchart, 1987; Rather, Bashir, Sheikh, Amin \&Zahgeer, 2013).

\section{Peer deviancy and Perceived social norms toward drug use:}

Risk for drug abuse is more when adolescents have friends who engage in drug use and problem behavior. Peer norms, generally measured in terms of peer approval of drug use, are positively correlated with peer drug use ( Ellickson\& Hays, 1992; Newcomb, Maddahian, Skager, \&Bentler, 1987). In both genders, peer deviancy in mid-adolescence mediated substance abuse at age 16 (Kirisci, Mezzich, Reynolds, Tarter and Aytaclar, 2009).

\section{School domain}

\section{School difficulties:}

Students that miss classes without telling their parents have higher chances of using tobacco, alcohol, and drugs. (Malta, Porto, Melo, Monteiro, Sardinha,Lessa ,2011).Higher degrees of behavioral and emotional school engagement predicted a significantly lower risk of substance use and involvement in delinquency. Substance use prevention programs and other health-risk reduction programs should include components (i.e., adolescents' participation in and emotional 
attachment to school) to capitalize on the protective role of the school context against youth risk behavior(Li, Zhang, Liu, Arbeit, Schwartz, Bowers, Lerner,2011).

\section{Community domain}

\section{Drug availability:}

Community in which he lives plays a big role in determining the drug use. Drug availability increases the risk for drug abuse in the community ( Mesic, Ramadani, Zunic, Skopljak, Pasagic, Masic 2013). Favorable attitudes towards drug abuse by the community also increases the drug use (Ahmed, 2005).

\section{Poverty:}

Poverty and drug abuse are interrelated problems. There is evidence that poverty is a considerable risk factor for drug abuse and vice versa, but that neither problem would be sufficient, by itself, to cause the other. There are however some clear links. Drug addicts generally use all or a large part of household income in order to buy drugs. One consequence is the pauperization (concerning food security, shelter, education, etc.) of the addict and the people living with him or her. Drug abusers are more often absent from work or work less productively, which can subsequently lead to loss of employment and income. Drugs are used to escape the reality of poverty or deal with the hardship experienced (Kaestner, 1999;Jadidiand Nakhaee , 2014).

\section{Protective factors:}

Female gender, high academic achievements and normal family functioning were found to be protective factors for drug abuse (Beato-Fernández, Rodríguez-Cano, Belmonte$\underline{\text { Llario, }}$ Pelayo-Delgado,2005).A medium financial status and, for females, a satisfying relationship with father were found to be protective factors(Scalese, Curzio, Cutrupi, Bastiani, Gori, Denoth, \&Molinaro,2014).Participation in extracurricular activities, Personality traits such as low thrillseeking behaviour and a propensity for inhibition were found to be protective factors

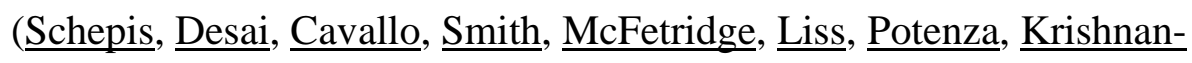

$\underline{\text { Sarin, }}$ 2011; Vitaro, Tremblay and Zoccolillo, 1999).

Consistent with previous findings, perceiving regular marijuana use as a risky behavior functions as a protective factor against the intention to use, use and occasional use of marijuana (LopezQuintero and Neumark,2010).

Parental supervision proves to be a protective influence and was found to reduce the risk of substance abuse in children of alcoholic fathers (Vitaro,Tremblay,\& Zoccolillo,1999).Parental controls were significantly related to adolescent drug use, with higher levels of control associated with less drug use (Fagan, Van Horn, Hawkins , \& Jaki, 2013).Children who come from strict 
homes where parents not only have negative attitudes about drinking and drugs but also monitor their children's academic progress and other activities also have less risk for alcoholism and drugs. Children who attend religious services frequently and/or who believe that religion is important in their lives have lower rates of chemical abuse. One study showed abuse at about $7 \%$ for religious teens and $17 \%$ for non-religious. Living with both parents is a protective factor for smoking, drinking, and drug use. Family supervision is also important for the prevention of such behavior. Sharing a meal with parents or responsible parties most days of the week and the fact that the parents know what the adolescents have done in their free time are also protective factors((Malta, Porto, Melo, Monteiro, Sardinha,\& Lessa,2011).

Anonconflictual and affectionate parent-adolescent relationship insulates the adolescent from drug use and in less alcohol use (Brook et al ,1989). Authoritative parenting style characterized by warmth, support, and clear rules and expectations (as opposed to those that were "authoritarian" or "permissive"), had low rates of adolescent alcohol and drug use (Baumrind, 1985) . Bennett, Wolin, and Reiss (1988) have found that even in alcoholic families, children tended to have better outcomes if the family was able to maintain some order and clear expectations for behavior.

Increased social support through betterment of teacher and peer relationship, increased care giving resources and care giving care giving environment in the school serves were found to be protective factors for drug abuse (Felner et al, 1985; Eggert and Herting, 1991;Benard, 1990).Children who were given the opportunities to plan and make decisions in their preschool environment involved in less drug abuse in adolescence stage (Berrueta- Clement et al, 1984; Schweinhart et al, 1986).

\section{CONCLUSION:}

Studies have identified many risks and protective factors for drug use among adolescence but which factors are more detrimental to drug use are not known and hence future studies need to focus on this aspect. It is also evident from the studies that drug abuse is related with multiple areas of life and thus intervention should focus on individual, family, school and community domains.

\section{REFERNCES}

1 Ahmed,H.S.(2005).Imbalance between drug and non-drug reward availability:A major risk factor for addiction European Journal of Pharmacology 526, 5,9-20.

2. Barnea,Z., Meir Teichman,M \& Rahav,G. (1992). Personality, cognitive, and interpersonal factors in adolescent substance use: A longitudinal test of an integrative model. Journal of Youth and Adolescence, 21, 2, 187-201.

3. Baumrind, D. (1985). Familial antecedents of adolescent drug use: A developmental perspec- tive. In Jones, C. L., and Battjes, R. J. (Eds.), Etiology of Drug Abuse: 
Implications for prevention. National Institute on Drug Abuse, Research Monograph Series 56, U.S. Government Printing Office, Washington, DC.

4. Beato-Fernández L, Rodríguez-Cano T, Belmonte-Llario A, Pelayo-Delgado E.(2005). Risk and protective factors for drug abuse in adolescents. A longitudinal research, 33 (6):352-358.

5. Benard, B. (1990). Youth service: from youth as problems to youth as resources. Illinois Prevention Forum10 (2).

6. Bennett, L, Wolin,S. \& Reiss, D. (1988). Deliberate family process: A strategy for protecting children of alcoholics. British Journal of Addiction, 83, 821-829.

7. Berrueta-Clement, J.R., Schweinhart, L.J., Barnett, W.S., Epstein, A.S. \&Weikart, D.P. (1984).Changed Lives: The Effects of the Perry Preschool Program on Youths Through Age 19, Ypsilanti, Mich.: High/Scope Press, Monographs of the HighScope Educational Research Foundation,8.

8. Bridgett, D.J., \&Mayes, L.C.(2011).Development of inhibitory control among prenatally cocaine exposed and non-cocaine exposed youths from late childhood to early adolescence: The effects of gender and risk and subsequent aggressive behavior.Neurotoxicology and Teratoogy ,33(1):47-60. doi: 10.1016/j.ntt.2010.08.002.

9. Brook, J. S., Whiteman, M., Gordon, A. S., \& Cohen, P. (1989). Changes in drug involvement: A longitudinal study of childhood and adolescent determinants. Psychological Reports, 65, 707 - 726.

10. Çırakoğlu, O. C., \&Işın, G. (2005). Perception of drug addiction among Turkish university students: Causes, cures, and attitudes. Addictive Behaviors, 30(1), 1-8.

11. Connie S. Y. Wong, Catherine S. K. Tang, \& Ralf Schwarzer (1996). Psychosocial Correlates of Substance Use: Comparing High School Students with Incarcerated Offenders in Hong Kong. Journal of Drug Education, 1996, Volume 27, Issue 2, 147 172.

12. Dielman TE, Butchart AT, Shope JT, Miller M (1990) Environmental correlates of adolescent substance use and misuse: Implications for prevention programs. International Journal of the Addictions, 25:855-880.

13. Dielman, T.E., Campanelli, P.C., Shope, J.T. and Butchart, A.T. (1987). Susceptibility to peer pressure, self-esteem, and health locus of control as correlates of adolescent substance abuse. Health Education Quarterly, 14, 207-221.

14. Drazdowski, T.K.,Jäggi,L., Borre, A., Kliewer, W.L .(2014). Use of prescription drugs and future delinquency among adolescent offenders.Journalof Substnce Abuse Treatment, 14:00145-7. doi: 10.1016/j.jsat.2014.07.008.

15. Eggert, L. L., \&Herting, J. R. (1991).Preventing teenage drug abuse: Exploratory effects of network social support .Youth and Society, 22(4), 482-534.

16. Ellickson, Phyllis L.; Hays, Ron D.On becoming involved with drugs: Modeling adolescent drug use over time.Health Psychology, Vol 11(6), 1992, 377-385. 
17. Fagan, A.A., Van Horn, M.L., Hawkins, J.D., \&Jaki, T. (2013).Differential Effects of Parental Controls on Adolescent Substance Use: For Whom Is the Family Most Important?Journal of Quantitative Criminology, 29(3), 347-368.

18. Farrell, A, D. \&Kamila W.S. (1998). Peer influences and drug use among urban adolescents: Family structure and parent-adolescent relationship as protective factors. Journal of Consulting and Clinical Psychology, 66(2), 248-258.

19. Felner,R.D., Janet F. Gillespie,F.J, \& Smith,R.(1985).Risk and Vulnerability in Childhood: A Reappraisal, Journal of Clinical Child Psychology, 14, (1), 2-4.

20. Gould,J.T. (2010). Addiction and Cognition.Addiction Science \& Clinical Practice, 5(2): 4-14.

21. Iacono, W.G., Carlson, S.R., Taylor,J., Elkins,I.J. and Matt Mcgue,M. (1999). Behavioral disinhibition and the development of substance-use disorders: Findings from the Minnesota Twin Family Study. Development and Psychopathology, 11, 869-900.

22. Jadidi,N., \&Nakhaee, N. (2014). Etiology of drug abuse: a narrative analysis.Journal of Addiction, 352835.doi: 10.1155/2014/352835. Epub 2014 Aug 26.

23. Kaestner,R. (1999). "Does Drug Use Cause Poverty?," NBER Chapters, in: The Economic Analysis of Substance Use and Abuse: An Integration of Econometrics and Behavioral Economic Research, 327-368. National Bureau of Economic Research, Inc.

24. Kande 1, Denise B., Ronald C. Kessler, and Rebecca Z. Margulies1978 "Antecedents of adolescent initiation into stages of drug use: a developmental analysis." Pp. · 73-99 in Denise B. Kandel( ed. ),Longitudinal Research on Drug Use. New York: Wiley.

25. Kandel, D.B. (1980). Drug and drinking behavior among youth. Annual Review of Sociology,6: 235-285.

26. Kirisci,L., Mezzich,A.C., Reynolds,M., Tarter,R.E and Aytaclar,S.(2009). Prospective Study of the Association BetweenNeurobehaviorDisinhibition and Peer Environment on Illegal Drug Use in Boys and Girls. American Journal of Drug Alcohol Abuse. 2009; 35(3): 145-150.

27. Kousha M, Shahrivar Z, Alaghband-Rad JSubstance Use Disorder and ADHD: Is ADHD a Particularly "Specific" Risk Factor?. Journal of Attention Disorders.. 2011 Nov 29.

28. Krosnick, J. A., \& Judd, C. M. (1982).Transitions in social influence at adolescence: Who induces cigarette smoking? Developmental Psychology, 18, 359-368.

29. Kumpfer, K.L.; Olds, D.L.; Alexander, J.F.; Zucker, R.A.; and Gary, L.E.(1998).Family etiology of youth problems. In: Ashery, R.S.; Robertson, E.B.; and Kumpfer K.L.; eds. Drug Abuse Prevention Through Family Interventions. NIDA Research Monograph No. 177. Washington, DC: U.S. Government Printing Office, pp. 42-77.

30. LeventKirisci, Ada C Mezzich, Maureen Reynolds, Ralph E Tarter, SemaAytacla. (2009).Prospective study of the association between neurobehaviordisinhibition and peer environment on illegal drug use in boys and girls. The American journal of drug and alcohol abuse, 35, 3, 145-150. 
31. Liang, W., \&Chikritzhs, T.(2014).Age at first use of alcohol predicts the risk of heavy alcohol use in early adulthood: A longitudinal study in the United States. The International Journal on Drug Policy, 14:00169-8. doi: 10.1016/j.drugpo.2014.07.001.

32. Li Y, Zhang W, Liu J, Arbeit MR, Schwartz SJ, Bowers EP, Lerner RM.(2011). The role of school engagement in preventing adolescent delinquency and substance use: A survival analysis. Journal of Adolescence, 34(6):1181-92.

33. Lopez-Quintero C, Neumark Y.(2010). Effects of risk perception of marijuana use on marijuana use and intentions to use among adolescents in Bogotá, Colombia.Drug Alcohol Dependence, 1,109(1-3):65-72.

34. Malta DC, Porto DL, Melo FC, Monteiro RA, Sardinha LM, Lessa BH.(2011).Family and the protection from use of tobacco, alcohol, and drugs in adolescents, National School Health Survey. Brazilian Journal of Epidemiology,14,166-77.

35. McCarthy DM, Miller TL, Smith GT, Smith JA.(2001). Disinhibition and expectancy in risk for alcohol use: Comparing black and white college samples. Journal of Studies on Alcohol, 62:313-321.

36. Harrington,M., Robinson,J., Shay-Lee.B., Sareen,J\&Bolton,J.M.(2011). A Longitudinal Study of Risk Factors for Incident Drug Use in Adults: Findings From a Representative Sample of the US Population Canadian Journal of Psychiatry, 56(11):686-69.

37. Martí,C.I., Fernández,M, Rodríguez,L.M(2011).Alcohol, drug and tobacco use amongst adolescents in Barcelona region.Revistade Enfermeria, 34(1):15-9.

38. Mesic, S., Ramadani, S., Zunic, L., Skopljak, A., Pasagic, A; Masic.I.(2013) Frequency of substance abuse among adolescents.Materia Socio-media,25(4):265-9.doi: 10.5455/msm.2013.25.265-269. Epub 2013 Nov 24.

39. Mirlashari J, Demirkol A, Salsali M, Rafiey H, Jahanbani J.Drug Alcohol Rev. 2011 .Early childhood Factors for Incident Drug Use in Adults: Findings From a Representative Sample of the US Population Canadian Journal of Psychiatry, 56(11):686-69.

40. Mirlashari J, Demirkol A, Salsali M, Rafiey H, Jahanbani J.Drug Alcohol Rev. 2011 .Early childhood experiences, parenting and the process of drug dependency among young people in Tehran, Iran. Drug and Alcohol Review, 5.

41. Moon, D.; Hecht, M.; Jackson, K.; and Spellers, R. (1999).Ethnic and gender differences and similarities in adolescent drug use and refusals of drug offers. Substance Use and Misuse 34(8):1059-1083.

42. Mousavi, F., Garcia, D., Jimmefors, A., Archer, T., Ewalds-Kvist, B.(2014). Swedish high-school pupils' attitudes towards drugs in relation to drug usage, impulsiveness and other risk factors. Peer Journal, 2:e410. doi: 10.7717/peerj.410. eCollection 2014.

43. National Institute on Drug Abuse (NIDA) (1997). Preventing drug use among children and adolescents.A research-based guide for parents,educators and community leaders. 2nd Edition,Maryland.NIH publication. 
44. Newcomb, M.D., Maddahian, E., Skager, R., \&Bentler, P.M. (1987). Substance abuse and psychosocial risk factors among teenagers: Associations with sex, age, ethnicity, and type of school.American Journal of Drug and Alcohol Abuse, 13, 413-433.

45. Ospina-Díaz,J.M., Herrera-Amaya,G.M., Manrique-Abril,F.G.(2012). Illegal psychoactive substance consumption amongst older schoolchildren in the city of Tunja, Colombia.Revista de SaludPublica (Bogota), 2:86-99.

46. Pilatti, A., Godoy, J.C., Brussino, S.A., \&Pautassi, R.M. (2013). Patterns of substance use among Argentinean adolescents and analysis of the effect of age at first alcohol use on substance use behaviors.Addictive Behaviours, 38(12):2847-50. doi: 10.1016/j.addbeh.2013.08.007. Epub 2013 Aug 14.

47. Rather, Y.H., Bashir, W., Sheikh, A.A, Amin, M.,\& Zahgeer, Y.A .(2013)Sociodemographic and Clinical Profile of Substance Abusers Attending a Regional Drug Deaddiction Centre in Chronic Conflict Area: Kashmir, India. The Malaysian Journal of Medical Sciences, 20(3):31-8.

48. Ridenour TA, Tarter RE, Reynolds M, Mezzich A, Kirisci L, Vanyukov M.(2009).Neuro behavior disinhibition, parental substance use disorder, neighborhood quality and development of cannabis use disorder in boys.Drug and Alcohol Dependence,1;102(13):71-77.

49. Rumpold,G., Klingseis,M., Dornauer,K., Kopp,M., Doering,S., Höfer,S., Mumelter,B\& Gerhard Schüssler,G.(2006). Psychotropic substance abuse among adolescents: a structural equation model on risk and protective factors. Substance use misuse, 41, 8, 1155-1169

50. Russell JM, Newman SC \& Bland RC.(1994). Drug abuse and dependence."ActaPsychiatricaScandinavica, 89:54-62.

51. Scalese, M., Curzio, O., Cutrupi, V., Bastiani, L., Gori, M., Denoth, F., \&Molinaro, S.(2014).Links between Psychotropic Substance Use and Sensation Seeking in a Prevalence Study: The Role of Some Features of Parenting Style in a Large Sample of AdolescentsJournal of Addiction,962178. doi: 10.1155/2014/962178. Epub 2014 Sep 21.

52. Schepis TS, Desai RA, Cavallo DA, Smith AE, McFetridge A, Liss TB, Potenza MN, Krishnan-Sarin S. (2011).Gender differences in adolescent marijuana use and associated psychosocial characteristics. Journal of Addiction Medicine 5(1):65-73.

53. Schlegel, R. P., Crawford, C. A. and Sanborn, M. D. (1977), "Correspondence and Mediational Properties of the Fishbein Model: An Application to Adolescent Alcohol Use," Journal of Experimental. Social Psychology, 13, 421-30.

54. Schweinhart,L.L., Weikart,P.D\&Larner,B.M. (1986).Consequences of three preschool curriculum models through age 15.Early Childhood Research Quarterly, 1, 1, 15-45.

55. Sher, K. J., \&Trull, T. J. (1994). Personality and disinhibitory psychopathology: Alcoholism and antisocial personality disorder. Journal of Abnormal Psychology, 103, 92-102. 
56. Stanton, W. R. \& Silva, P.A. (1992).A longitudinal study of the influence of parents and friends on children's initiation of smoking. Journal of Applied Developmental Psychology,13, 423-43.

57. Torok, M., Darke, S., Kaye, S., \&Shand, F. (2014).The association of early-life and substance use risks to violent offending among injecting drug users. Drug and Alcohol Review. doi: 10.1111/dar.12126.

58. Vermeulen-Smit, E., Ten Have, M., Van Laar, M., \&De Graaf R.(2014).Clustering of health risk behaviours and the relationship with mental disorders.Journal of Affective Disorders, 171:111-119. doi: 10.1016/j.jad.2014.09.031.

59. Vitaro, F., Tremblay, R.E\& Zoccolillo, M.(1999). Alcoholic father, adolescent drug abuse and protective factor.Canadian Journal of Psychiatry, 44(9),901-8.

60. Wong, C. S. Y., Tang, C. S. K., \&Schwarzer, R. (1997). Psychosocial correlates of substance use: Comparing high school students with incarcerated offenders in Hong Kong.Journal of Drug Education, 27(2), 147-172.

61. Zucker, R. A. (1979). Developmental aspects of drinking through the young adult years.In H. T. Blane\& M. E. Chafetz (Eds.), Youth, alcohol, and social policy (pp. 91146). New York: Plenum. 